http://dx.doi.org/10.22319/rmcp.v10i1.4512

Artículo

\title{
Aislamiento e identificación de bacterias ácido lácticas con potencial probiótico para becerros del altiplano mexicano
}

Patricia Landa-Salgado ${ }^{a}$

Yesenia Caballero-Cervantes $^{\mathrm{a}}$

Efrén Ramírez-Bribiesca* ${ }^{\text {a* }}$

Ana María Hernández-Anguiano ${ }^{\mathrm{a}}$

Luz Mariana Ramírez-Hernández

David Espinosa-Victoria ${ }^{a}$

David Hernández-Sánchez ${ }^{\mathrm{a}}$

${ }^{a}$ Colegio de Postgraduados, Campus Montecillo. Km 36.5 Carretera México Texcoco. Montecillo Estado de México. CP 56230.

${ }^{\mathrm{b}}$ Benemérita Universidad Autónoma de Puebla. Facultad de Medicina.

*Autor de correspondencia: efrenrb@colpos.mx

\section{Resumen:}

Los becerros neonatos son expuestos continuamente a un amplio rango de microorganismos habitantes del ambiente, y a patógenos causantes de diarrea. El objetivo de este estudio fue aislar e identificar bacterias acido lácticas (BAL) de la mucosa oral de becerros, calostro y leche de vacas Holstein. El aislamiento de BAL se realizó en caldo y placas con medio ManRogosa Sharp (MRS). Una vez purificadas las colonias bacterianas, se realizaron pruebas morfológicas y bioquímicas para la caracterización de BAL. Se aislaron 16 colonias bacterianas, de las cuales se clasificaron en 12 de la mucosa oral, 2 en leche y 2 en calostro. 
Estas colonias se evaluaron a $\mathrm{pH}$ ácido $(4.0$ y 4.5) y sales biliares (SB: 0.3 y $1.5 \mathrm{~g}$ ). Posteriormente se identificaron con el Sistema API50CHL. Las especies aisladas con resistencia a $\mathrm{pH}$ de 4 y 1.5 de SB fueron: Leuconostoc mesenteroides, Pediococcus pentosaceus, Lactobacillus plantarum, Lactobacillus crispatus y Lactococcus lactis. Estas colonias cuentan con un potencial probiótico para ser usadas en becerros.

Palabras clave: Becerras, Probióticos, Aislamiento, Resistencia.

Recibido: 01/06/2017

Aceptado: 27/02/2018

\section{Introducción}

La cría de becerras para reemplazo presenta algunos problemas, como el mal suministro de calostro, alimentación con sustitutos de leche de baja calidad y cambios repentinos en la ración ${ }^{(1)}$. Estas malas prácticas provocan diarreas ocasionadas principalmente por enteropatógenos, provocando tasa de mortalidad en más de $10 \%$, durante las primeras semanas de $\operatorname{vida}^{(2)}$. Para reducir la mortalidad se recurre al uso de antibióticos, pero la resistencia a las cepas patógenas afecta negativamente la salud de los animales ${ }^{(3,4)}$. En consecuencia, diferentes laboratorios veterinarios promueven el uso de probióticos hechos de bacterias ácido lácticas (BAL), prometiendo beneficios en la prevención y disminución de diarreas, con mejora en la ganancia de peso. Sin embargo, los productos deben de cumplir con requisitos idóneos para ser probióticos eficientes. Por ejemplo, el número mínimo de microorganismos que se requiere en el intestino del becerro para generar una adecuada salud, es de $10^{6}$ unidades formadoras de colonias (UFC) $/ \mathrm{ml}^{(1)}$.

Los ensayos clínicos realizados en la década pasada, demostraron que el $45 \%$ de probióticos comercializados, tienen nula eficiencia de las BAL en la prevención de diarreas en becerras, e incluso parece que estos en lugar de favorecer, incrementaron la incidencia y severidad de diarreas $^{(4,5)}$, y no hay respuesta para mejorar la ganancia diaria de peso y la conversión alimenticia $^{(6,7)}$. En la actualidad estos mismos parámetros son similares por los laboratorios que comercializan probióticos en las unidades de producción ganadera lechera. Las cepas usadas tienen baja viabilidad de microorganismos probióticos presentes en los productos comerciales; además se han encontrado especies de bacterias diferentes a las citadas en las etiquetas ${ }^{(8)}$. En cuanto a su origen, las bacterias probióticas provienen de diferentes regiones 
geográficas e incluso de otras especies animales, lo que ocasiona baja viabilidad y actividad probiótica $^{(4)}$. El objetivo del estudio se enfocó en el aislamiento y la identificación de bacterias con potencial probiótico (resistencia a pH ácido y sales biliares (SB)) en ganado Holstein de la región del altiplano de México.

\section{Material y métodos}

\section{Aislamiento de bacterias de mucosa oral y de calostro}

Se utilizaron cinco becerros lactantes de 30 días de edad y cinco vacas adultas de segundo parto en lactancia, raza Holstein Friesan del rancho del Colegio de Postgraduados, Campus Montecillo. También se tomaron muestras de calostro de cinco vacas Holstein recién paridas del Rancho privado Xalapango. Ambos sitios están ubicados en el valle de Texcoco, Estado de México, entre los paralelos $18^{\circ} 21^{\prime}$ y $20^{\circ} 17^{\prime} \mathrm{N}$ y $98^{\circ} 36^{\prime}$ y $100^{\circ} 36^{\prime} \mathrm{O}^{(9)}$.

\section{Toma de muestras}

Mucosa oral: se tomaron muestras duplicadas de exudado de la mucosa oral por becerro lactante, frotando por 3 seg el hisopo ( $3 \mathrm{M}^{\mathrm{TM}} \mathrm{Swab}-\mathrm{Sampler}$ ), previo a la ingesta de alimento matutino. Cada hisopo se colocó dentro de un tubo estéril con $10 \mathrm{ml}$ de agua peptonada buferada (RS96010BPW).

Calostro y leche: antes del muestreo se realizó la limpieza, desinfección y despunte de los pezones y se colectaron $5 \mathrm{ml}$ de calostro y $10 \mathrm{ml}$ de leche por grupo de vacas asignadas. Las muestras se depositaron en frascos estériles manteniéndose a $4{ }^{\circ} \mathrm{C}$ y trasladándose inmediatamente al laboratorio para su análisis, según lo descrito por la Norma Mexicana ${ }^{(10)}$. 


\section{Procesamiento de las muestras}

Las muestras fueron pre-enriquecidas (para favorecer el crecimiento de las BAL) en medio de cultivo líquido ${ }^{(11)}$. Se tomó por duplicado $1 \mathrm{ml}$ de la suspensión bacteriana de mucosa oral y se depositó en tubos con $5 \mathrm{ml}$ de caldo mann rogosa sharp (MRS). Los tubos inoculados se dividieron en dos grupos aleatorios. El primero se mantuvo en condiciones aerobias y el segundo en condiciones anaerobias, ambos a $37{ }^{\circ} \mathrm{C}$ por $18 \mathrm{~h}$. En el caso de las muestras de calostro y leche, se tomaron $200 \mu$ por duplicado y también se depositaron en tubos con 5 $\mathrm{ml}$ de caldo MRS. Los tubos inoculados se mantuvieron en un desecador con ambiente anaerobio (inducido con una vela encendida) por $18 \mathrm{~h}$ a $37^{\circ} \mathrm{C}$. Al final del tiempo, a cada tubo se le extrajo una muestra con la asa bacteriológica y se sembraron en cajas Petri con medio sólido $\mathrm{MRS}^{(12)}$, incubando a $37{ }^{\circ} \mathrm{C}$ por $48 \mathrm{~h}$, en condiciones anaerobias y aerobias. Como grupos testigo positivos y negativos, se incluyeron una cepa de Lactobacillus casei ATCC y una de E.coli O42, donadas por la Universidad Autónoma de Querétaro.

\section{Selección de las bacterias}

Los cultivos fueron seriados en el proceso de sembrado, por las duplicaciones en el medio solido MRS, se acumularon 54 colonias con características de BAL, de acuerdo al tamaño, forma, superficie, elevación, borde y color ${ }^{(13)}$. La caracterización de las cepas se realizó con las pruebas de tinción de Gram, morfología celular, tinción de esporas y la prueba de catalasa $^{(12)}$. Adicionalmente, se efectuaron las pruebas de producción de indol y de motilidad, en medio de cultivo SIM (sulfhídrico, indol, motilidad), hidrólisis de la gelatina y reducción de nitratos ${ }^{(14)}$. Se realizó una segunda selección de las colonias aisladas, considerando los mejores puntajes y la morfología idónea de cocobacilos y bacilos. Entre éstas, se identificaron 27 colonias, las cuales se reprodujeron en $5 \mathrm{ml}$ de caldo MRS por $18 \mathrm{~h}$, para su evaluación como bacterias probióticas. De cada suspensión bacteriana obtenida se tomaron $800 \mu \mathrm{l}$ por duplicado y se transfirieron a tubos Eppendorf con $800 \mu \mathrm{l}$ de glicerol estéril al 50\% como crioprotector, conservándose a $-20{ }^{\circ} \mathrm{C}$ por $3 \mathrm{~h}$ y posteriormente a $-80{ }^{\circ} \mathrm{C}$ por tiempo indefinido. 


\title{
Determinación de la resistencia y supervivencia de las cepas seleccionadas a condiciones gastrointestinales
}

\author{
Resistencia a pH ácido
}

Preparación de inóculo: de las 27 colonias obtenidas, se hizo nueva selección. Se escogieron 16 de ellas por seguir manteniendo una morfología bien definida de cocobacilos y bacilos. El cepario final quedó integrado con 12 aislamientos de la mucosa oral, 2 de leche y 2 de calostro. Todas las colonias seleccionadas se reactivaron a $-20{ }^{\circ} \mathrm{C}$ y temperatura ambiente; luego se transfirió cada muestra en tubos con $5 \mathrm{ml}$ de caldo MRS. Posteriormente se incubaron a $37^{\circ} \mathrm{C}$ en condiciones anaerobias por $24 \mathrm{~h}$ y nuevamente $1 \mathrm{ml}$ de cada suspensión bacteriana $\left(10^{6} \log _{10} \mathrm{UFC} / \mathrm{ml}\right)$ se adicionó en tubos con $9 \mathrm{ml}$ de caldo MRS, incubándose por $18 \mathrm{~h}$. La suspensión bacteriana obtenida se centrifugó a 2,056 xg por $10 \mathrm{~min}$; el paquete celular se resuspendió en $10 \mathrm{ml}$ de leche semidescremada (Alpura ${ }^{\circledR} 2000^{\circledR}$ ) esterilizada (110 ${ }^{\circ} \mathrm{C}$ por $15 \mathrm{~min}$ ) para realizar la prueba de resistencia a pH 4.5 y 4.0. La leche se utilizó como medio protector y como vehículo de los microorganismos probióticos ${ }^{(15)}$, siguiendo el protocolo descrito por Fernández de Palencia et $a l^{(16)}$. La resistencia a condiciones de $\mathrm{pH}$ ácido se evaluó con la disminución con las células bacterianas. La reducción de $\mathrm{pH}$ se hizo con alícuotas controladas de $\mathrm{HCl}$ al IN. Cuando el $\mathrm{pH}$ se estabilizó a 4.5 y 4.0, las muestras se incubaron a $37^{\circ} \mathrm{C}$ por $10 \mathrm{~min}$. Posteriormente se tomó $1 \mathrm{ml}$ de cada suspensión para hacer diluciones seriadas, y de cada dilución se tomaron $100 \mu$ l, sembrándose en agar MRS, para estimar la viabilidad de las células bacterianas. Las colonias evaluadas a pH de 4.5 y 4.0 , se sembraron a diluciones $10^{-6}$ y $10^{-7}$ en una suspensión de leche.

\section{Resistencia a la exposición de sales biliares en placas de microtitulación}

Las colonias seleccionadas se expusieron a SB en placas de microtitulación (BD Primaria ${ }^{\mathrm{TM}}$ ) con capacidad de $3.5 \mathrm{ml}$ por pozo. Se utilizó una placa por cada concentración y previo al establecimiento de la prueba, se prepararon dos matraces con $100 \mathrm{ml}$ caldo MRS; uno con 
$0.3 \mathrm{~g}$ y otro con $1.5 \mathrm{~g}$ de SB de bovino $\left(\mathrm{Oxgall} \mathrm{Difco}^{\mathrm{TM}}\right)^{(17,18)}$. En la prueba se incluyeron dos testigos negativos: solución MRS-con SB sin bacteria y un MRS-sin SB con bacteria. La prueba se estableció por triplicado y cada colonia ocupó seis pozos de la placa. Adicionalmente, se depositaron $2 \mathrm{ml}$ de solución (MRS-con SB sin bacteria) y $20 \mu \mathrm{l}(1: 10$ $\mathrm{v} / \mathrm{v}$ ) de suspensión bacteriana por $18 \mathrm{~h}$ de crecimiento. Después de $1 \mathrm{~h}$ de inoculación y previo a la incubación de las placas, se midió la densidad óptica (DO) de cada suspensión a $600 \mathrm{~nm}$ con un espectrofotómetro (GENESYS $10 \mathrm{UV} /$ Thermo Spectronic). Posteriormente, las placas con los tratamientos se incubaron a $37^{\circ} \mathrm{C}$ en condiciones anaerobias, a las $24 \mathrm{~h}$ se registró nuevamente la lectura de la DO.

\section{Identificación bioquímica y colección de cepas con potencial probiótico}

Las colonias con características de BAL se identificaron con el sistema APICHL (System; BioMerieux SA, France). En el procedimiento, se reactivaron las colonias en $5 \mathrm{ml}$ de caldo MRS en condiciones anaerobias a $37^{\circ} \mathrm{C}$ por $18 \mathrm{~h}$, adicionando el diluyente $50 \mathrm{CH}$ (suministrado con la galería: API50CH), de acuerdo a las indicaciones del producto. La suspensión preparada se usó para llenar 50 microtubos de la galería; las cúpulas de estos microtubos se llenaron con aceite mineral estéril, para generar condiciones anaerobias. Las galerías inoculadas (una por colonia) se mantuvieron a $37^{\circ} \mathrm{C}$ por $48 \mathrm{~h}$ para establecer el perfil bioquímico de cada colonia. La interpretación de los resultados se hizo con la identificación de cambio de color en el medio API50CHL de cada microtubo; el azul indicó un valor negativo, y el amarillo y negro indicaron valores positivos (hoja de seguridad placas). Los datos registrados se analizaron con el sistema computarizado Apiweb®. La Figura 1, resume en tres fases las secuencias metodológicas que se realizaron para identificar y asilar las BAL con potencial probiótico. 
Figura 1: Diagrama de aislamiento y selección de bacterias probioticas

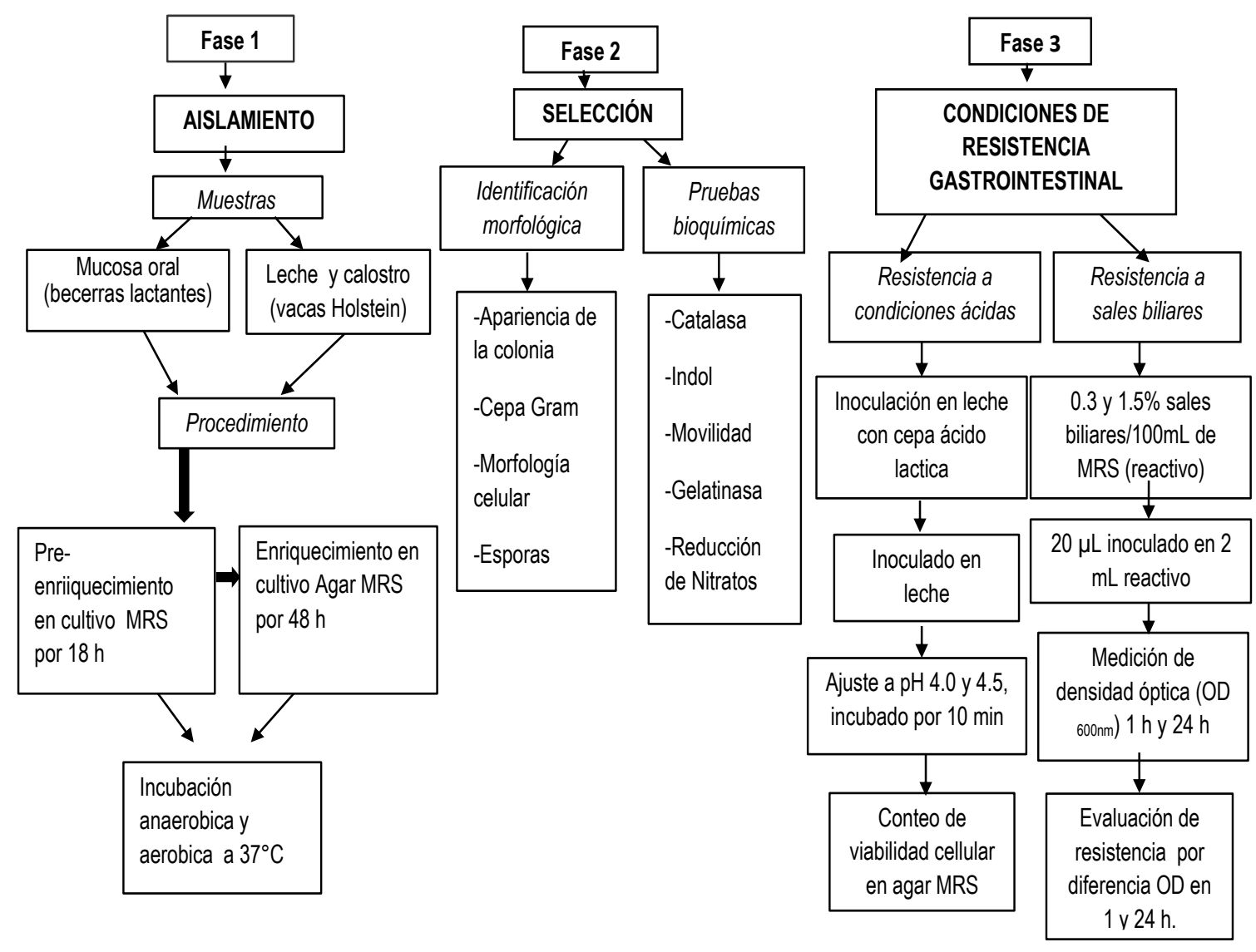

\section{Análisis estadístico}

Los datos que fueron analizados con pruebas estadísticas inicialmente, presentaron una distribución normal (Prueba de Kolmogorov-Smirnov) y homogeneidad de varianzas (prueba de Levene). Posteriormente se realizó el análisis de varianza y la prueba de Tukey para la comparación de medias. Se utilizó un nivel mínimo de significancia de $0.5 \%$, utilizando el paquete estadístico SPSS Ver. $15^{(19)}$. 


\section{Resultados y discusión}

\section{Aislamiento y crecimiento de colonias}

Las colonias seleccionadas en el medio anaerobio tuvieron mejor crecimiento que las cultivadas en condiciones aerobias. Las colonias por la morfología seleccionada fueron cocobacilos y bacilos, gram positivas, sin presencia de esporas, catalasa negativa, sin motilidad, sin producción de indol, gelatinasa y negativas a la reducción de nitratos.

Las muestras de la mucosa oral tuvieron un tamaño promedio de 2 a $4 \mathrm{~mm}$ de diámetro con características morfológicas homogéneas de forma circular, elevación convexa, borde entero, superficie lisa y color blanco sin pigmentos. Del total de las muestras de leche, solo el $20 \%$ tuvo crecimiento de colonias bacterianas, el tamaño promedio fue de $2.5 \mathrm{~mm}$ de diámetro. Mientras las colonias aisladas de calostro presentaron un color beige y tamaño variable de entre 1 y $5 \mathrm{~mm}$ de diámetro. Generalmente, las bacterias probióticas se han aislado de las mucosas oral, vaginal e intestinal de becerros sanos y en muestras de leche ${ }^{(11,20)}$. En este estudio, las colonias de la mucosa oral y de leche, tuvieron la capacidad de los lactobacilos para adaptarse y sobrevivir ${ }^{(13)}$, debido a la presencia del grupo hemina, que les permite activar la cadena respiratoria con el oxígeno como aceptor de electrones ${ }^{(21)}$. Los diferentes géneros de las BAL comparten características morfológicas, metabólicas y fisiológicas como la forma, elevación, margen, color y reacciones bioquímicas ${ }^{(13)}$. Sus características morfológicas celulares y pruebas bioquímicas han sido reportadas como básicas, para la selección de cepas probióticas ${ }^{(5,22)}$, y se recomienda complementarlo con estudios moleculares ${ }^{(23)}$. 


\section{Viabilidad de las cepas seleccionadas con base en su resistencia a pH ácido}

El Cuadro 1 muestra las poblaciones de las colonias evaluadas a diferentes $\mathrm{pH}$. El crecimiento con el pH testigo de 6.5, promedió 9.07 $\log _{10} \mathrm{UFC} / \mathrm{ml}$. Mientras que a $\mathrm{pH} 4.0$, el crecimiento disminuyó $(P<0.001)$ a $5.09 \log _{10} \mathrm{UFC} / \mathrm{ml}$. Las colonias que no crecieron con un $\mathrm{pH}$ de 4 fueron eliminadas y no se incluyeron en el cepario final; éstas fueron las dos colonias de leche. Específicamente las bacterias probióticas para poder llegar al sitio de acción y mantenerse viables, deben ser capaces de resistir el $\mathrm{pH}$ ácido y la presencia de $\mathrm{SB}$ en el duodeno $^{(24)}$. Varios autores ${ }^{(7,25)}$ han desarrollado metodologías para evaluar la resistencia de cepas probióticas en condiciones gástricas. Por ejemplo, L.plantarum y L. acidophilus, crecieron y fueron viables a $\mathrm{pH} 5.0$, mientras que a $\mathrm{pH} 4.0$ y 3.0 se detuvieron estas actividades $^{(16)}$; lo que coincide con la información obtenida en este estudio a un pH de 4.0. Esta sensibilidad de las cepas, puede estar relacionado con la respuesta ácido tolerante o resistencia adquirida. Broadbent et $a l^{(26)}$ compararon células de $L$. casei crecidas a pH 6.0 (testigo) contra grupos de células adaptadas $\mathrm{pH} 4.5$ por 10 min y células adaptadas a $\mathrm{pH} 4.5$ por 20 min, presentando disminución de viabilidad de hasta $4.0 \log _{10}$ y de 0.7 a $2.4 \log _{10}$ $\mathrm{UFC} / \mathrm{ml}$ en 10 y $20 \mathrm{~min}$ de adaptación, respectivamente. Los autores mencionan que la adaptación de las células al ácido provocó cambios en la composición de lípidos de la membrana, mostrando un dramático incremento de ácidos grasos saturados e insaturados, así como la fermentación maloláctica y acumulación intracelular de histidina. Por otro lado, otros autores ${ }^{(27,28,29)}$ reportan habilidades de las bacterias probióticas para sobrevivir a la digestión acida del estómago; ésta es variable y depende de cada cepa, lo que explica las diferencias en resistencia, como ocurrió en el estudio a pH 4.0. Comúnmente, los lactobacilos tienen mejor crecimiento a $\mathrm{pH} 4.0$ vs $\mathrm{pH} 3.0^{(30)}$. Pocas colonias llegan a resistir el $\mathrm{pH} 3$, comúnmente 4 de 200 cepas BAL sobreviven ${ }^{(31)}$. 
Cuadro 1: Conteo de colonias recobradas en agar Man-Rogosa-Sharpe (MRS) inmediatamente después de la exposición a pH ácido y su identificación bioquímica

\begin{tabular}{|c|c|c|c|c|}
\hline $\begin{array}{l}\text { Número } \\
\text { de cepas }\end{array}$ & $\begin{array}{c}\text { T1 } \\
\text { pH } 6.5\end{array}$ & $\begin{array}{c}\text { T2 } \\
\text { pH } 4.5\end{array}$ & $\begin{array}{c}\text { T3 } \\
\text { pH } 4.0\end{array}$ & $\begin{array}{c}\text { Identificación bioquímica de } \\
\text { cepas ácido lácticas con } \\
\text { sistema API (API 50CHL) }\end{array}$ \\
\hline$\sim$ & 9.40 & 9.21 & 5.74 & \\
\hline \multicolumn{5}{|l|}{ Mucosa } \\
\hline 1 & 8.77 & 8.40 & 5.08 & Leuconostoc mesenteroides \\
\hline 2 & 9.46 & 8.43 & 5.49 & Leuconostoc mesenteroides \\
\hline 3 & 9.02 & 9.36 & 5.09 & Pediococcus pentosaceus \\
\hline 4 & 9.06 & 7.23 & 4.83 & Lactobacillus plantarum \\
\hline 5 & 8.28 & 7.67 & 5.06 & Lactobacillus plantarum \\
\hline 6 & 8.78 & 8.47 & 4.01 & Lactobacillus salivarius \\
\hline 7 & 8.71 & 8.49 & 6.43 & Leuconostoc mesenteroides \\
\hline 8 & 9.36 & 8.39 & 6.47 & Lactobacillus crispatus \\
\hline 9 & 9.39 & 9.11 & 5.44 & Leuconostoc mesenterodes \\
\hline 10 & 9.37 & 8.68 & NG & Lactobacillus brevis \\
\hline 11 & 9.36 & 8.84 & NG & Lactobacillus brevis \\
\hline 12 & 8.82 & 8.48 & 3.33 & Leuconostoc mesenteroides \\
\hline \multicolumn{5}{|l|}{ Leche } \\
\hline 13 & 9.02 & 8.14 & NG & Lactobacillus brevis \\
\hline 14 & 9.15 & 8.31 & NG & Lactobacillus brevis \\
\hline \multicolumn{5}{|l|}{ Calostro } \\
\hline 15 & 9.32 & 9.14 & 5.34 & Lactococcus lactis \\
\hline 16 & 9.32 & 8.95 & 4.52 & Leuconostoc mesenteroides \\
\hline Media & $9.07 \pm 0.33^{\mathrm{a}}$ & $8.50 \pm 0.54^{\mathrm{b}}$ & $5.09 \pm 0.89^{c}$ & \\
\hline
\end{tabular}

Treatment, $\sim$ correspond to positive control strain L. casei. Data are mean values of three replicates and correspond to $\log _{10} \mathrm{CFU} / \mathrm{mL}$ NG: No growth.

a,b Different letters in the mean value \pm Std. deviation, indicate significant differences $P<0.03$.

Por otro lado, la resistencia y crecimiento a la exposición de SB se ha realizado con concentraciones desde 0.1 hasta $4.0 \%{ }^{(32,33)}$. En el presente estudio, las BAL continuaron creciendo a altas concentraciones de SB (1.5 g), siendo un parámetro importante para los microorganismos que componen los productos comerciales ${ }^{(34,35)}$, sin embargo no es comúnmente considerado. En un estudio similar ${ }^{(36)}$ se evaluó la resistencia de L. plantarum a la exposición de varias concentraciones de SB de origen porcino $(0.01,0.05,0.10$ y 0.15 $\mathrm{g}$ ); el crecimiento de la cepa fue monitoreado por $24 \mathrm{~h}$ con mediciones de DO, y la mayor 
tasa de crecimiento se dio con la menor concentración de SB. De este modo, la densidad final alcanzada por esta cepa con $0.10 \mathrm{~g}$ SB fue tres veces más baja con respecto al testigo. Mientras que, en este estudio, las colonias tuvieron una DO final de 2.5 veces más baja, con una concentración de $0.3 \mathrm{~g}$, a diferencia del grupo testigo. La resistencia a SB de bacterias productoras de ácido láctico (Streptococcus thermophilus, Lactobacillus delbrueckii subsp bulgaricus y Lactococcus lactis) y bacterias probióticas (L. acidophilus, L. casei, L. rhamnosus y Bifidobacterium) se ha reportado con dosis mayores de 0.3 a $1 \%$ de $\mathrm{SB}^{(37,38)}$. S. thermophilus fue la cepa más sensible a la concentración de $0.5 \mathrm{~g} \mathrm{SB}$ y Lactococcus lactis fue resistente con $1 \mathrm{~g}$ de SB. Todas las cepas probióticas mostraron resistencia a $1.5 \mathrm{~g} \mathrm{SB}$, aunque la resistencia a la exposición de SB puede diferir entre los miembros del género Lactobacillus, debido a la habilidad de algunas cepas para colonizar y estabilizarse rápidamente en el intestino de las becerras ${ }^{(7)}$. Estudios in vivo, administrando L. acidophilus a becerras, fueron capaces de incrementar el número total de lactobacilos en el yeyuno de los animales de 13 a $39 \%$ y por otro lado, cepas de L. plantarum y Lactococcus acidilactici presentaron mejor crecimiento con condiciones de $\mathrm{pH} 4.0$ y $0.3 \mathrm{~g}$ de $\mathrm{SB}^{(5)}$. En este estudio, las BAL mostraron mejor tolerancia a la exposición de $\mathrm{SB}$ que a $\mathrm{pH} 4.0$; principalmente la resistencia a la exposición prolongada al $\mathrm{pH}$ ácido y a altas concentraciones de $\mathrm{SB}$ de las BAL seleccionadas, pueden ser buenos parámetros en capacidad de sobrevivencia y colonización durante el tránsito intestinal ${ }^{(28,39)}$.

\section{Identificación bioquímica de las cepas con el sistema API50CHL y viabilidad a la exposición con sales biliares}

El Cuadro 1 también muestra los resultados obtenidos en la identificación de las colonias con base al perfil de fermentación de carbohidratos (API50CHL-BioMerieux). Los resultados tuvieron un intervalo de 96 y $99 \%$ de efectividad. De las colonias aisladas de la mucosa oral, 6 se identificaron como Lactobacillus, 5 como Leuconostoc y 1 como Pediococcus. Las muestras de calostro fueron Leuconostoc y Lactobacillus.

El promedio de la DO obtenida en cada una de las cepas evaluadas, incrementó 3.1 veces $(P<0.05)$, después de $24 \mathrm{~h}$ de incubación, con la concentración de $0.3 \mathrm{~g} \mathrm{SB}$, respecto a la primera lectura. Por otra parte, cuando se aumentó la concentración de SB a $1.5 \mathrm{~g}$, la DO incrementó 2.7 veces a las 24 h. Los efectos principales muestran disminución $(P<0.023)$ de OD con el mayor valor de SB e incrementó $(P<0.0001)$ la OD desde 1 a 24 h (Cuadro 2 ). Algunos estudios que han evaluado el beneficio de las bacterias probióticas en becerras 
reportan datos contradictorios, tal vez por la falta de diversidad en los probióticos por regiones geográficas y por comercializar cepas poco viables. Por tal motivo, es difícil encontrar secuencias de experimentos con una misma cepa ${ }^{(40)}$. En América Latina la comercialización de productos probióticos para becerras es limitada y dudosa; la mayoría de las empresas solo cuentan con cepas de L. acidophilus cepa KA1-A 8 con 3,000 billones de UFC/dosis y con L. casei con 3,000 millones de UFC/dosis, sin especificación para su uso en becerras. Otras empresas promueven productos con Lactobacillus rhamnosus y Bifidobacterium lactis con 1 x $10^{11}$ UFC por unidad dosis o con 50 unidades para la aplicación directa en 1,000 L de leche; pero en el producto no se especifica el origen de las cepas, quizás son obtenidas de otras especies animales o alimentos, por lo que no se consideran buenas opciones. Por ejemplo, cuando se administra cepas probióticas de humanos al ganado, estos microorganismos no tienen una colonización duradera en el intestino, debido a las diferencias fisiológicas y alimentarias entre las especies ${ }^{(41,42)}$; razón por la cual en este estudio se realizó el aislamiento de colonias con potencial probiótico de una región ganadera de bovinos Holstein. Actualmente, para el ganado los géneros de bacterias probióticas más utilizadas, son Lactobacillus, Enterococcus, Bifidobacterium, Lactococcus y Leuconostoc ${ }^{(43)}$, Lactobacillus plantarum, L. acidophilus, L. casei, L. salivarius y Lactococcus lactis ${ }^{(5,44,45)}$, L. fermentum VC3B-08, W. hellinica V1V-30 and L. farciminis $\mathrm{B} 4 \mathrm{~F}-06^{(20)}$.

Tabla 2: Promedios de densidad óptica (DO) en el crecimiento de cepas ácido lácticas con dos concentraciones de sales biliares $(\mathrm{SB}, \%)$ por 1 y 24 horas

\begin{tabular}{|c|c|c|c|c|c|c|c|c|c|c|c|}
\hline \multicolumn{6}{|c|}{ Tratamiento } & \multicolumn{6}{|c|}{ Efectos principales } \\
\hline & \multicolumn{2}{|c|}{$0.3 \%$ SB } & \multicolumn{2}{|c|}{$1.5 \% \mathrm{SB}$} & \multirow{2}{*}{ EEM } & \multirow{2}{*}{$0.3 \%$ SB } & \multirow{2}{*}{$1.5 \% \mathrm{SB}$} & \multirow{2}{*}{ EEM } & \multirow{2}{*}{$1 \mathrm{~h}$} & \multirow{2}{*}{$24 \mathrm{~h}$} & \multirow{2}{*}{ EEM } \\
\hline 1 & $1 \mathrm{~h}$ & $24 \mathrm{~h}$ & $1 \mathrm{~h}$ & $24 \mathrm{~h}$ & & & & & & & \\
\hline $\mathrm{DO}$ & 0.33 & 1.02 & 0.31 & 0.84 & 0.03 & 0.68 & 0.57 & 0.02 & 0.32 & 0.93 & 0.02 \\
\hline$P>F$ & \multicolumn{2}{|c|}{0.008} & \multicolumn{2}{|c|}{0.008} & & \multicolumn{2}{|c|}{0.023} & & \multicolumn{3}{|c|}{0.0001} \\
\hline
\end{tabular}

EEM= Error estándar de la media.

\section{Conclusiones e implicaciones}

Se seleccionaron 16 colonias BAL de ganado Holstein. Lactobacillus brevis aislado en muestras de la mucosa oral y leche, no creció en pH ácido (4.0). Las colonias seleccionadas 
fueron Leuconostoc mesenteroides, Pediococcus pentosaceus, Lactobacillus plantarum. Lactobacillus crispatus y Lactococcus lactis. Por las características evaluadas, se asume que las colonias identificadas, cuentan ampliamente con un potencial probiótico para ser evaluadas directamente en el tracto gastrointestinal de becerros.

\section{Literatura citada:}

1. Soto LP, Frizzo LS, Avataneo E, Zbrun MV, Bertozzi E, Sequeria G, Signorini ML, Rosmini MR. Design of macrocapsules to improve bacterial viability and supplementation with a probiotic for young calves. Anim Feed Sci Technol 2011;(165):176-183.

2. Shu Q, Gill HS. Immune protection mediated by the probiotic Lactobacillus rhamnosus HN001 (DR20TM) against Escherichia coli O157:H7 infection in mice. FEMS Inmunol Med Microbiol 2002;(34):59-64.

3. Frizzo LS, Zbrun MV, Soto LP, Signorini ML. Effects of probiotics on growth performance in young calves: A meta-analysis of randomized controlled trials. Anim Feed Sci Technol 2011;(169):147-156.

4. Rosmini MR, Sequeira GJ, Guerrero I, Marti LE, Dalla R, Frizzo L, Bonazza JC. Producción de prebióticos para animales de abasto: Importancia del uso de la microbiota intestinal indígena. Rev Mex Ing Quim 2004;(3):181-191.

5. Rodriguez-Palacios A, Staempfli HR, Duffield T, Weese JS. Isolation of bovine intestinal Lactobacillus plantarum and Pediococcus acidilactici with inhibitory activity against Escherichia coli O157 and F5. J Appl Microbiol 2008;(106):393-401.

6. Seifzadeh S, Aghjehgheshlagh FM, Abdibenemar H, Seifdavati J, Navidshad B. The effects of a medical plant mix and probiotic on performance and health status of suckling Holstein calves. Italian J Anim Sci 2017;(16):44-51.

7. He ZX, Ferlisi B, Eckert E, Brown HE, Aguilar A, Steele MA. Supplementing a yeast probiotic to pre-weaning Holstein calves: feed intake, growth and fecal biomarkers of gut health. Anim Feed Sci Technol 2017;(226):81-87.

8. Wannaprasat W, Koowatananukul C, Ekkapobyotin C, Chuanchuen R. Quality analysis of commercial probiotic products for food animals. Southeast Asian J Trop Med Public Health 2009;(40):1103-1112.

9. Municipio de Texcoco. https://es.wikipedia.org/wiki/Municipio_de_Texcoco. 
10. NOM-109-SSA1-1994: Proyecto de Norma Oficial Mexicana, Bienes y Servicios. Procedimiento para la toma, manejo y transporte de muestras de alimentos para su análisis microbiológico. 1994. Diario Oficial de la Federación. 1994.

11. Coeuret V, Dubernet S, Bernardeau M, Gueguen M, Vemoux JP. Isolation, characterisation and identification of lactobacilli focusing mainly on cheeses and other dairy products. Dairy Sci Technol Le Lait 2003;(83):269-306.

12. Pérez MJ, Vázquez JR, Rodríguez MC, Miranda RE, Romo AL, Nader GE. Procedimientos de laboratorio para bacteriología y micología veterinarias. Universidad Nacional Autónoma de México, México, DF. 1987.

13. Kandler O, Weiss N. nonsporing Gram positive rods. Bergey's Manual of systematic bacteriology. $10^{\text {th }}$ ed (ed. Sneath, Mair, Sharp and Holt), Baltimore, USA: The Williams and Wilkins Co; 1992.

14. Haro M, Ruiz V, Guerra F. Manual para la identificación de microorganismos de interés veterinario. México: Trillas; 2012.

15. Bove P, Gallone A, Russo P, Capozzi V, Albenzio M, Spano G, Fiocco D. Probiotic features of Lactobacillus plantarum mutant strains. Appl Microbiol Biotechnol 2012;(96):431-441.

16. Fernández de Palencia P, López P, Corbí AL, Peláez C, Requena T. Probiotic strains: survival under simulated gastrointestinal conditions, in vitro adhesion to Caco-2 cells and effect on cytokine secretion. Eur Food Res Technol 2008;(227):1475-1484.

17. Pereira DI, McCartney AL, Gibson GR. An in vitro study of the probiotic potential of a bile-salt-hydrolyzing Lactobacillus fermentum strain, and determination of Its cholesterol-lowering properties. Appl Environ Microbiol 2003;(8):4743-4752.

18. Tinrat D, Saraya S, Chomnawang MT. Isolation and characterization of Lactobacillus salivarius MTC 1026 as a potential probiotic. J Gen Appl Microbiol 2011;(57):365-378.

19. SPSS $®$ Version 15 software (SPSS Inc., Chicago, IL). Copyright @ 2006 de SPSS Inc.

20. Sandes S, Alvim L, Silva B, Acurcio L, Santos C, Campos M, Santos C, Nicoli J, Neumann E, Nunes A. Selection of new lactic acid bacteria strains bearing probiotic features from mucosal microbiota of healthy calves: Looking for immunobiotics through in vitro and in vivo approaches for immunoprophylaxis applications. Microbiol Res 2017;(200):1-13.

21. Ekinci F, Gurel M. Effect of using propionic acid bacteria as an adjunt culture in yogurt production. J Dairy Sci 2007;(91):892-899. 
22. Jaramillo GD, Meléndez AP, Sánchez MO. Evaluación de la producción de bacteriocinas a partir de Lactobacillus y Bifidobacterias. Rev Venez Cienc Tecnol Aliment 2010;(1):193-209.

23. Marroki A, Zúñiga M, Kihal M, Pérez- Martínez G. Characterization of lactobacillus from algerian goat's milk based on phenotypic, 16sr DNA sequencing and their technological properties. Brazilian J Microbiol 2011;(42):158-171.

24. Salminen S, Von Wright A, Morelli L, Marteau P, Brassart D, de Vos WM, et al. Demonstration of safety of probiotics-a review. Int J Food Microbiol 1998;(44):93-106.

25. Dunne C, O’Mahony L, Murphy L. In vitro selection criteria for probiotic bacteria of human origin: correlation with in vivo findings. Am J Clin Nutr 2001;(73):386-392S.

26. Broadbent JR, Larsen RL, Deibel V, Steele JL. Physiological and transcriptional response of Lactobacillus casei ATCC 334 to acid stress. J Bacteriol 2010;(192):24452458.

27. Charteris WP, Kelly PM, Morelli L, Collins JK. Development and application of an in vivo methodology to determine the transit tolerance of potentially probiotic Lactobacillus and Bifidobacterium species in the upper human gastrointestinal tract. J Appl Microbiol 1998;(84):759-76.

28. Chou LS, Weimer B. Isolation and characterization of acid- and bile-tolerant isolates from strains of Lactobacillus acidophilus. J Dairy Sci 1999;(82):23-31.

29. Xanthopoulos V, Litopoulou-Tzanetaki E, Tzanetakis N. Characterization of Lactobacillus isolates from infant faeces as dietary adjuncts. Food Microbiol 2000;(17):205-215.

30. Jin LZ, Ho YW, Abdullah N, Jalaludin S. Acid and bile tolerance of Lactobacillus isolated from chicken intestine. Lett Appl Microbiol 1998;(27):183-185.

31. Prasad J, Gill H, Smart J, Gopal PK. Selection and characterization of Lactobacillus and Bifidobacterium strains for use as probiotics. Int Dairy J 1998;(8):993-1002.

32. Gómez-Zavaglia A, Kociubinski G, Perez P, De Antoni G. 1Isolation and characterization of Bifidobacterium strains for probiotic formulation. J Food Prot 1998;(61):865-873.

33. Kociubinski G, Pérez P., De Antoni G. Screening of bile resistance and bile precipitation in lactic acid bacteria and bifidobacteria. J Food Pro 1999;(62):905-912.

34. Carr F, Chill D, Maida N. The lactic acid bacteria: A literature survey. Crit Rev Microbiol 2002;(28):281-370. 
35. Foditsch C, Pereira RVV, Ganda EK, Gómez MS, Marques EC, Santin T, Bicalho RC. Oral Administration of Faecalibacterium prausnitzii decreased the incidence of severe diarrhea and related mortality rate and increased weight gain in preweaned dairy heifers. PLOS ONE 2015;(10):e0145485.

36. Bron PA, Grangette C, Mercenier A, de Vos WM, Kleerebesem M. Identification of Lactobacillus plantarum genes that are induced in the gastrointestinal tract of mice. $\mathbf{J}$ Bacteriol 2014;(186):5721-5729.

37. Naidu AS, Biblack WR, Clemens RA. Probiotic spectra of lactic acid bacteria. Critical Rev Food Sci Nutrition 1999;(38):13-126.

38. Lee YK, Nomoto K, Salminen S, Gorbach S. Handbook of probiotics. Lee YK editior. New York, USA: John Wiley \& Sons. Inc; 1999.

39. Haller D, Colbus H, Ganzle MG, Scherenbacher P, Bode C, Hammes WP. Metabolic and functional properties of lactic acid bacteria in the gastro-intestinal ecosystem: a comparative in vitro study between bacteria of intestinal and fermented food origin. Syst Appl Microbiol 2001;(24):218-226.

40. Maragkoudakis PA, Zoumpopoulou G, Miaris C, Kalantzopoulos G, Pot B, Tsakalidou E. Probiotic potential of Lactobacillus strains isolated from dairy products. Int Dairy $\mathbf{J}$ 2006;(16):189-199.

41. Ewaschuk JB, Naylor JM, Chirino-Trejo M, Zello GA. Lactobacillus rhamnosus strain GG is a potential probiotic for calves. Can J Vet Res 2004;(68):249-253.

42. Ewaschuk JB, Zello GA, Naylor JM. Lactobacillus GG does not affect D-lactic acidosis in diarrheic calves, in a clinical setting. J Vet Int Med 2006;(20):614-619.

43. Gaggia F, Mattarelli P, Biavati B. Probiotics and prebiotics in animal feeding for safe food production. Int J Food Microbiol 2010;(141):S15-S28.

44. Cebeci A, Gürakan C. Properties of potential probiotic Lactobacillus plantarum strains. Food Microbiol 2003;(20):511-518.

45. Vinderola CG, Reinheimer JA. Lactic acid starter and probiotic bacteria: a comparative in vitro study of probiotic characteristics and biological barrier resistance. Food Res Int 2003;(36):895-904. 